\title{
Burton-Roberts on presupposition and negation ${ }^{1}$
}

\author{
PIETER A. M. SEUREN
}

Nijmegen University

(Received 26 April 1989; revised 19 October, 1989)

\section{BuRton-ROBERTS' CONTENTIONS}

In his paper 'On Horn's dilemma: presupposition and negation' BurtonRoberts (1989a) presents an ambitious programme, formulated right at the outset. He seeks to establish three points:

(i) Under the 'standard logical definition of presupposition' a presuppositional semantics is INCOMPATIBLE with a SEMANTICALLY AMBIGUOUS NEGATION operator (SAN), on pain of the theory being rendered 'empirically empty and theoretically trivial'.

(ii) From this it follows that the one unambiguous negation is presupposition preserving. Cases that have been identified as presupposition-cancelling negation should be re-analysed as 'instances of a pragmatic phenomenon', not unlike what has been proposed in Horn (1985), that is as METALINGUISTIC NEGATION (MN).

(iii) This pragmatic analysis of $\mathrm{MN}$ itself implies a presuppositional semantics', that is to say 'a presuppositional theory of truth-value gaps'.

To those familiar with presupposition theory in its various present-day guises this programme will seem ambitious. Contention (i) goes against the mainstream of current opinion, where it is held that, given the available facts, negation must be taken to be ambiguous if presupposition is taken to be a logico-semantic relation. Burton-Roberts proclaims this to be a mistaken notion, thereby taking on a heavy burden of proof. Contention (ii) is also surprising, as it denies ambiguity to negation while at the same time a presupposition-cancelling and non-truth-functional but pragmatic metalinguistic negation is distinguished from a presupposition-preserving truthfunctional semantic negation. The same goes for contention (iii), according to which the promised pragmatic analysis is said to imply a presuppositional semantics. We shall have a look at these three contentions first, whereby the strictly logical aspects will be taken together, to be followed by the pragmatic claims. We will then consider some facts, largely taken from Seuren (1985), not brought to bear by Burton-Roberts, yet clearly relevant and disturbing.

[I] I am grateful to the editor of $J L$ and two anonymous reviewers, whose comments have helped me considerably in sharpening my arguments and finding the right tone. 
A constant theme in the critique will be Burton-Roberts' unwarranted attempts at pre-empting empirical issues on invalid a priori grounds.

\section{2. 'PRESUPPOSITIONAL SEMANTICS REQUIRES ONE UNIQUE AND MINIMAL NEGATION'}

Burton-Roberts begins by characterizing what a presuppositional semantics amounts to. It is based on a 'logical definition of presupposition', which, for the purposes of his argument, ${ }^{2}$ can be given as follows:

\section{(I) A PRESUPPOSES B iff A entails B and Not-A entails B.}

This, Burton-Roberts then asserts, has the consequences that:

'(i) A and Not-A share their presuppositions, and (ii) where A presupposes $B$, presupposition-failure (in the form of the non-truth of B) results inevitably in A's having a third logical status other than true or false. Indeed, the definition in (I) is equivalent to that in (2) and to that in (3):

(2) A presupposes B iff Not-A presupposes B.

(3) A presupposes B iff B is true in every state of affairs in which A is true, and $A$ has a third logical status (other than true or false) when $B$ is not true.'

From the point of view of (propositional) logic, these claims do not seem to be warranted. He fails to specify in what kind of logic the 'consequences' (i) and, especially, (ii) are supposed to hold. If the logic is strictly bivalent, i.e. classical, (ii) does not hold. All that follows then is that any presupposed B is a logically necessary truth, since, by contraposition, Not-B would lead to the contradiction 'A and Not-A' and is therefore impossible. BR's (ii) does follow when (I) is extended with the clause: 'and B is not a logically necessary truth'. So let us do that. The consequence is a non-bivalent, i.e. non-classical, logical system.

But even then one cannot say that (1) is equivalent to (2) and (3). The alleged equivalence of ( $\mathrm{I}$ ) and (2) is difficult to see: (I) defines presupposition in terms of entailment, whereas (2) defines the notions 'presupposition of $A$ ' and 'presupposition of Not-A' in terms of each other. How these can be called equivalent is unclear, though it is not difficult to construct a logical system and define negation in it in such a way that (2) will FOLLOW FROM (I).

[2] Burton-Roberts' own definition of presupposition is presented in Burton-Roberts ( $1989 \mathrm{~b}$ ). The definition given there must, unfortunately, be characterized as logically incoherent, or anyway as making it impossible for any sentence to have contingent presuppositions (see Seuren (to appear b)). This is, however, not at issue here. We shall act as though he accepts the definitions as given here, not only, as he says, 'for the purpose of the argument', but also because it transpires (see below at the end of section 2) that he actually adheres to them, in spite of what he defends in ( $1989 \mathrm{~b}$ ). 
But let us forget about (2), and concentrate for a moment on (3). ${ }^{3}$ We will then see that (I) and (3) are by no means equivalent. The demonstration of this non-equivalence will prove useful for an adequate insight into the questions at hand. ${ }^{4}$

Let us make an inventory of all possible combinations of the values TRUE (T), FALSE (F), and whatever the now no longer excluded THIRD (3) might amount to for the sentences A, B, and Not-A. In doing that I shall make use of Van Fraassen's (197I) system of presentation by means of VALUATIONS, i.e. truth-value assignments to all sentences considered. Each valuation represents a state of affairs as defined by the truth-values assigned to the sentences in question. For the sentences A, B, an Not-A the following complete set of valuations can be constructed:

(4) Non-bivalent field of valuations $\mathscr{U}$ for A, B, and Not-A

\begin{tabular}{cccccccccccccccc}
\hline U & I & 2 & 3 & 4 & 5 & 6 & 7 & 8 & 9 & I0 & II & I2 & I3 & I4 & I5 \\
\hline A & T & F & 3 & T & F & 3 & T & F & 3 & T & F & 3 & T & F & 3 \\
B & T & T & T & F & F & F & 3 & 3 & 3 & T & T & T & F & F & F \\
Not $-\mathrm{A}$ & $\mathrm{T}$ & $\mathrm{T}$ & $\mathrm{T}$ & $\mathrm{T}$ & $\mathrm{T}$ & $\mathrm{T}$ & $\mathrm{T}$ & $\mathrm{T}$ & $\mathrm{T}$ & $\mathrm{F}$ & $\mathrm{F}$ & $\mathrm{F}$ & $\mathrm{F}$ & $\mathrm{F}$ & $\mathrm{F}$ \\
$\mathscr{U}$ & $\mathrm{I} 6$ & 17 & 18 & $\mathrm{I} 9$ & 20 & $2 \mathrm{I}$ & 22 & 23 & 24 & 25 & 26 & 27 & & & \\
\hline $\mathrm{A}$ & $\mathrm{T}$ & $\mathrm{F}$ & 3 & $\mathrm{~T}$ & $\mathrm{~F}$ & 3 & $\mathrm{~T}$ & $\mathrm{~F}$ & 3 & $\mathrm{~T}$ & $\mathrm{~F}$ & 3 & & & \\
B & 3 & 3 & 3 & $\mathrm{~T}$ & $\mathrm{~T}$ & $\mathrm{~T}$ & $\mathrm{~F}$ & $\mathrm{~F}$ & $\mathrm{~F}$ & 3 & 3 & 3 & & & \\
Not $-\mathrm{A}$ & $\mathrm{F}$ & $\mathrm{F}$ & $\mathrm{F}$ & 3 & 3 & 3 & 3 & 3 & 3 & 3 & 3 & 3 & & & \\
\hline
\end{tabular}

The valuations are numbered from $\mathrm{I}$ to 27 . All possible $3^{3}$ combinations of T, F and 3 for the three sentences A, B, and Not-A are thus given.

The question is now: what does 3 represent? Burton-Roberts is rather vague on this. On pp. 96-7 he informs the reader that he will follow Quine (1960: 177). This, unfortunately, is a passage where the American philosopher, though no mean figure, manifests considerable confusion:

Even such truth-value gaps can be admitted and coped with, perhaps best by something like a logic of three truth values. But they remain an irksome complication, as complications are that promise no gain in understanding.

[3] Note that the formulation in (3): ' $B$ is true in every state of affairs in which $A$ is true' is by definition equivalent to 'A entails $B$ ' or $A=B$. Definition (3) thus says that $A$ presupposes $B$ iff $A \vDash B$ and non-truth of B results in 'a third logical status' for A.

[4] Some readers may find the following pages hard to read. To those I apologise, but I hope they realize that logical theory, like mathematical theory, has no choice but to be formal. Other readers, more versed in logic, might be surprised at the unfamiliar character of some of the notions presented. These I simply ask to concentrate on the logical and mathematical correctness of the analysis. They will see that, in the end, standard classical logic has not suffered at all, but has perhaps rather been enriched by these innovations. 
Quine had obviously not investigated the metalogical question of gaps and further truth-values with anything like the rigour he has shown elsewhere (but then, Quine was never much in favour of what he perceived as unorthodoxy). In any case, Burton-Roberts does seem to follow Quine in being unclear about the issue. Having first (97) left the issue more or less open, he decides later on (I06) definitely in favour of interpreting ' 3 ' as a gap. Meanwhile (104) he refers to Dummett (1973), who argues, on good grounds, that what Frege (and Strawson) took to be a truth-value gap had better be reinterpreted as a third value. Burton-Roberts' disappointing comment is that 'in these terms, the distinction between a presuppositional and a non-presuppositional logic reduces to a merely terminological one'. We are not much helped by what we read on p. I05, where he makes further comments on multivalued systems:

They are purely formal systems. They are not specifically intended to reconstruct the intuitive notion of the radical kind of failure constituted by the failure to make a statement, a failure induced by presuppositionfailure.

Surely, there is nothing against a 'purely formal system' which is 'specifically intended to reconstruct' some intuitive notion. What else do we do in science? Moreover, a trivalent logic would be intended to reconstruct the intuitive notion of a radically false statement, which can be rendered true only by denying a presupposition, whereas a bivalent logic with gaps would be intended to reconstruct the intuitive notion of 'failure to make a statement'. The two kinds of reconstruction are, as is easily seen, rather different from one another. It is indeed surprising, then, to read on p. 106 that the appeal to a bivalent logic with gaps is made as a means of reconstructing the intuition of a very radical kind of failure, the failure to make an assertion that has a truth-value. I am calling this "statement failure".' Should one conclude from this that Burton-Roberts denies to a trivalent logic the power of reconstruction of an intuitive notion which he grants to a bivalent logic with gaps? I think his position on these matters is highly puzzling. ${ }^{5}$

There is, of course, a fundamental distinction between accepting truthvalue gaps on the one hand, and a third truth-value on the other. The difference is that gaps fall outside the system of truth-functions, whereas a third value takes part in them. A truth-function, such as logical negation, maps truth-values onto truth-values, for example, $\mathrm{T}$ onto $\mathrm{F}$ and $\mathrm{F}$ onto $\mathrm{T}$, for

[5] This impression is reinforced by statements like: 'Dummett, Evans and I do seem to be agreed, however, on the existence of a correlation between an enlargement of the set of falsity/negation operators in a logic and the interpretation of that logic as being strictly multivalent, as having an enlarged set of actual truth-values as such' (105). Burton-Roberts seems to be presenting here what is necessary by definition as though it were a matter of opinion. 


\section{BURTON-ROBERTS' CONTENTIONS}

classical negation. But it does not accept a non-truth-value as input: if 3 is regarded as a gap, then a truth-function rejects it as input, and consequently gives no output, as Burton-Roberts himself points out on p. 97. For negation this is usually expressed by saying that if $A$ has no value (i.e. figures as 3 ), then Not-A likewise lacks a value (and figures as 3). The straightforward table for classical negation in a system with two truth-values and gaps (one often speaks of a 'bivalent system with gaps') is thus:

(5) Truth-table for classical negation in a bivalent logic with gaps

\begin{tabular}{ll}
\hline A & $\neg \mathrm{A}$ \\
\hline $\mathrm{T}$ & $\mathrm{F}$ \\
$\mathrm{F}$ & $\mathrm{T}$ \\
3 & 3 \\
\hline
\end{tabular}

If, however, 3 is interpreted as a truth-value along with $\mathrm{T}$ and $\mathrm{F}$, we have a truly three-valued (trivalent) system. In such a system there is no necessity to let a 3 input result in a 3 output, since other possibilities are now available.

In a truly trivalent system, all values other than $T$ are different kinds of falsity, that will occur under different kinds of violation of truth-conditions. In such a system a negation operator can be defined in a variety of ways, whereby we require that the operator be truth-functional, that it does not map $T$ onto $T$, and that at least one value other than $T$ be mapped onto $T$, these being considered constitutive properties of whatever deserves the name of negation. Under these conditions, a logic with three truth-values (and no gaps) allows for no less than Io distinct negation operators, as is shown in (6):

(6) Possible negations in a trivalent logic without gaps

\begin{tabular}{ccccccccccc}
\hline $\mathrm{A}$ & $\mathrm{N}_{1}$ & $\mathrm{~N}_{2}$ & $\mathrm{~N}_{3}$ & $\mathrm{~N}_{4}$ & $\mathrm{~N}_{5}$ & $\mathrm{~N}_{6}$ & $\mathrm{~N}_{7}$ & $\mathrm{~N}_{8}$ & $\mathrm{~N}_{9}$ & $\mathrm{~N}_{10}$ \\
\hline $\mathrm{T}$ & $\mathrm{F}$ & $\mathrm{F}$ & $\mathrm{F}$ & $\mathrm{F}$ & $\mathrm{F}$ & 3 & 3 & 3 & 3 & 3 \\
$\mathrm{~F}$ & $\mathrm{~T}$ & $\mathrm{~F}$ & $\mathrm{~T}$ & $\mathrm{~T}$ & 3 & $\mathrm{~T}$ & $\mathrm{~F}$ & $\mathrm{~T}$ & $\mathrm{~T}$ & 3 \\
3 & $\mathrm{~F}$ & $\mathrm{~T}$ & $\mathrm{~T}$ & 3 & $\mathrm{~T}$ & $\mathrm{~F}$ & $\mathrm{~T}$ & $\mathrm{~T}$ & 3 & $\mathrm{~T}$ \\
\hline
\end{tabular}

It is not too difficult to prove (Weijters, 1985 ; Seuren, 1988) that classical bivalent logic defined over the truth-functional operators $\neg$ (classical negation), $\wedge$ (conjunction) and/or $\vee$ (disjunction) is the minimal case of an infinite set $\mathscr{L}$ of possible $n$-valued logics all defined over these same operators in such a way that $\neg$ turns $T$ into $F$ and all other values into $T, \wedge$ selects the highest and $\vee$ the lowest value of the pair or arguments. In other words, the 
number of values in a logical system is irrelevant as long as the operators over which it is defined are as described above. Of the ten negations in (6), clearly, $\mathrm{N}_{3}$ is the classical negation $\urcorner$. It will be clear that, in a system defined over just $(\neg, \wedge, \vee)$, there is little point in extending the number of truth-values beyond the minimum of 2 , since any further values are logically vacuous. Clearly, a three-valued logic with ten negations is not of much use, certainly not for the description of the logical properties of natural language sentences. There is, however, a simple and elegant way of constraining the number of negations so that an $n$-valued system will have, besides the classical negation $\neg, n$-I SPECIFIC negations. This is done in the following way.

Every $n$-valued logic $\mathscr{C}_{n} \in \mathscr{L}$ has a hierarchy of specific negations neg $_{1} \ldots$ neg $_{\mathrm{n}-1}$ such that for every sentence $p$ of the language $L$ the universe $\mathscr{U}$ of possible valuations ('worlds') contains a hierarchy of subuniverses $\mathscr{U}(p)_{1}, \ldots, \mathscr{U}(p)_{n-1}$ with the following properties: (i) $\mathscr{U}(p)_{\mathrm{n}-1}=\mathscr{U}$, (ii) each $\mathscr{U}(p)_{\mathrm{i}} \subseteq \mathscr{U}(p)_{\mathrm{i}+1} \quad(\mathrm{I} \leqslant \mathrm{i}<\mathrm{n}-\mathrm{I}), \quad$ (iii) neg denotes ('expresses') $\mathscr{U}(p)_{1}-/ p /($ ' $/ p /$ ' stands for the set of valuations or 'worlds' in which $p$ has the value $T$ ), and (iv) each subsequent $n^{2} g_{i}(I<i \leqslant n-1)$ denotes $\mathscr{U}(p)_{\mathrm{i}}-\mathscr{U}(p)_{\mathrm{i}-1}$. Logics with more than two values and with the negations as here specified can be called PRESUPPOSITIONAL LOGICS. Thus, given a threevalued presuppositional logic $\mathscr{C}_{3}$ and a sentence $a$, the universe $\mathscr{U}$ will be stuctured, for $a$, as in Figure 1 .

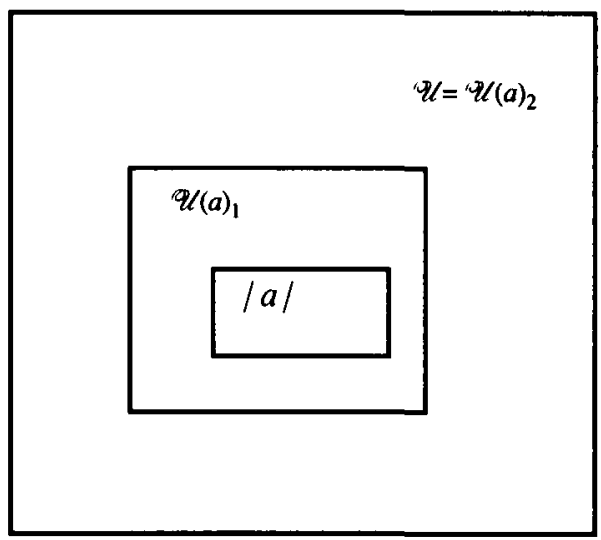

Figure 1 . The structuring of $\mathscr{U}$ for sentence $a$ in a trivalent presuppositional calculus

Presuppositional logics have the property that the disjunction of all their specific negations is equivalent to the classical negation. Thus, for $a, \operatorname{neg}_{1}(a)$ $\vee$ neg $_{2}(a) \cong \neg a$. A little ciphering will show that for a trivalent presuppositional logic neg is $\mathrm{N}_{4}$ of (6) above, and neg $_{2}$ is $\mathrm{N}_{2}$ of (6). ${ }^{6}$ neg $_{1}$ is the

[6] For a detailed discussion of these matters see Seuren (1988). Note that the similarity of the table for neg ${ }_{1}\left(=N_{4}\right.$ of $(6)$ ) with the table given for $\neg$ in (5) is deceptive: in (5) 3 stands for a gap in a bivalent system, and can be read as: 'neither true nor false', whereas in (6) it stands for a further falsity value and can be read as 'neither true nor minimally false'. 
MINIMAL NEGATION $(\sim)$, which turns MINIMAL FaLSITY into truth and preserves presuppositions, and neg $_{2}$ is the RADICAL NEGATION $(\simeq)$, turning RADICAL FALSITY into truth and cancelling presuppositions, as described in Seuren (1984), (1985), (1988). We can now say that a trivalent presuppositional calculus has the minimal and the radical negations as its SPECIFIC NEGATIONS. Their disjunction equals classical negation. The other negation operators listed in (6) have no function in a trivalent presuppositional calculus.

This illustrates the difference between a logic with gaps and a logic with three (or more) values. Let us now revert to (4). We can now see that many of the projected valuations of (4) will become INADMISSIBLE (in Van Fraassen's (1971) terms) if not is defined as a negation. Which valuations will become inadmissible will depend on whether we interpret 3 as a gap or as the third value, and, if the latter, which of the available negations we choose as a logical rendering for not.

If 3 in (4) is regarded as a truth-value gap there is only one possible negation, the classical negation as given in (5). Under that truth-function, the set of valuations in (4) that are not ruled out (declared 'inadmissible') is $\{2,5,8,10,13,16,21,24,27\}$, as is easily checked. The same holds for the interpretation of 3 as the third value, and of not as the minimal negation $(\sim)$. Let us express this by saying that

$$
\mathscr{U}(\sim)=\mathscr{U}\left(\neg_{\mathrm{gap}}\right)=\{2,5,8,10, \mathrm{I} 3, \mathrm{I} 6,2 \mathrm{I}, 24,27\} .
$$

Analogously, if 3 is taken to be the third value and not is translated as the radical negation $(\simeq)$, then:

$$
\mathscr{U}(\simeq)=\{3,6,9, \mathrm{I} 0, \mathrm{II}, \mathrm{I} 3, \mathrm{I} 4, \mathrm{I} 6, \mathrm{I} 7\}
$$

and again, if 3 is a real truth-value and not is the classical negation $(\neg)$, then:

$$
\mathscr{U}(\neg)=\{2,3,5,6,8,9,10,13,16\}
$$

Now we can come to the point. If presupposition is defined as some sort of entailment relation, as in (I) or (3) above, then, if A presupposes $B(A \gg B)$, further restrictions on the respective $\mathcal{U}$ 's are required. What restrictions will be required will depend on three decisions: whether we interpret 3 as a gap or as the third value; whether we take definition (I) or definition (3); and, if the former, whether we take $\sim, \simeq$, or $\neg$ as the logical rendering of not. We will then see that the results will differ for almost each choice we make. Only for some specific choices will the results be the same. Let us look at this in detail.

If we take (3) as the definition of the presupposition relation, and we read Burton-Roberts as intending that ' $B$ is not true' should be taken to mean that $B$ has either the value $F$ or the value 3 (or, for that matter, falls into the 
truth-value gap), then, if not is the minimal negation, one will easily see that $\mathscr{U}(\sim)$ is further restricted to $\{2,10,21,24,27\}$, or:

$$
\mathscr{U}(\sim)_{\mathrm{A} \gg \mathrm{B}(3)}=\{2,10,2 \mathrm{I}, 24,27\} .
$$

Likewise :

$$
\mathscr{U}(\simeq)_{\mathrm{A} \gg \mathrm{B}(3)}=\{3,6,9, \mathrm{I} \mathrm{O}, \mathrm{II}\}
$$

and:

$$
\mathscr{U}(\neg)_{\mathrm{A} \gg \mathrm{B}(3)}=\{2,3,6,9,10\} .
$$

But under definition ( $\mathrm{I}$ ), according to which ' $\mathrm{A} \gg \mathrm{B}$ ' requires that ' $\mathrm{A} \vDash \mathrm{B}$ and $N o t-A \models B$ ', the results are different, at least for the radical and the classical negation - unless we interpret 3 as a truth-value gap and not as the third value, because in that case $\mathscr{U}(\sim)_{\mathrm{A} \gg \mathrm{B}(3)}=\mathscr{U}(\sim)_{\mathrm{A} \gg \mathrm{B}(1)}=$ $\mathscr{U}(\neg \text { gap })_{\Lambda \gg B(1)}$. The results of $\mathscr{U}$-restriction under definition (I) and under the various negations allowed for by a truly trivalent calculus (or under the one negation allowed for in a system with gaps) are as follows:

$$
\begin{aligned}
& \mathscr{U}(\sim)_{\mathrm{A}} \gg \mathrm{B}(1)=\mathscr{U}(\neg \text { gap })_{\mathrm{A} \gg \mathrm{B}(1)}=\{2,10,21,24,27\} \\
& \mathscr{U}(\simeq)_{\mathrm{A}} \gg \mathrm{B(1)}=\{3,10,11,14,17\} \\
& \mathscr{U}(\neg)_{\mathrm{A} \gg \mathrm{B}(1)}=\{2,3,10\}
\end{aligned}
$$

The different admissibility conditions for valuations under the definitions (3) and (I), respectively, show that definition (I) is NOT equivalent to definition (3), and that it makes a great deal of difference whether we regard the 'third logical status' as a gap or as a real truth-value. Burton-Roberts' contentions that under 'the standard logical definition of presupposition' negation must be unambiguous and presupposition-preserving, and that definition (I) is equivalent to definition (3) are tenable only on the assumption that we have a two-valued system with gaps. This means that he in fact adopts the old Frege-Strawson analysis of presuppositions, which assumes precisely such a logic, a fact which he does not deny. On the contrary, he makes it quite clear that he does work with the Strawsonian notion of presupposition. But what makes his argument so strange is that he presents this position as in some way an a priori necessity, whereas, in fact, there is quite a choice of alternatives.? What the best alternative is will

[7] Cf. for example this passage on p. I06: 'In Section 2 I addressed some general considerations of principle which suggest that it is not open to the proponent of presuppositionally induced truth-value gaps to appeal to a further (external, presupposition-cancelling') negation. Negation must be unambiguously 'presuppositionpreserving'. First, the impossibility of more than one negation in a bivalent system with gaps is not something to be 'suggested' but a mathematical necessity of such systems, as has been shown above (cf. note 4). Then, the second sentence, which claims that negation must be unambiguous and minimal, stands in no relation to the first since there is no $a$ priori or, for that matter, empirical, necessity requiring a bivalent logic with gaps. 


\section{BURTON-ROBERTS' CONTENTIONS}

depend crucially on the empirical adequacy of the descriptions and analyses presented in terms of it.

The empirical factor is not entirely forgotten by Burton-Roberts, but he tries to pre-empt the empirical issue by bringing to bear what look like $a$ priori arguments. While theoretically leaving room for a truly trivalent system with two negations, he maintains that one can rule this out, again, on a priori grounds, because such a system is possible only at the cost of 'rendering the theory empirically empty and theoretically trivial' (95). And this is so, he claims, because given the two negations that would figure in such a logic the denotation of the one (the 'internal' negation) is included in the denotation of the other (the 'external' negation): 'The more specific internal understanding entails the more general external understanding; for a semantics that includes the external operator, it is impossible to demonstrate that it also includes a distinct internal operator' (100). The point is reiterated on p. 102:

A logical theory of presupposition (defined as in (I) above) which includes a presupposition-cancelling negation is trivial and empirically empty because it is quite simply unfalsifiable. No putative counter-example to the original definition could possibly be a counter-example since they are wiped out at a stroke by this 'presupposition-cancelling' negation. This theory would effectively be a theory capable of handling its own proper counter-examples.

His conclusion is anyway that it is useless even to try to establish SAN because that alleged ambiguity is of a kind which, on a priori grounds, cannot be established.

Unfortunately, however, Burton-Roberts overlooks some of his own presuppositions. The first is that if SAN is proposed it must be an ambiguity between classical ('external') and minimal ('internal') negation. We have just seen, however, that it may well make more sense to distinguish between radical and minimal negation, in which case there is no entailment relation either way between the two. Furthermore, there is the assumption that if negation is in some way ambiguous, then ALL POSSIBLE USES OF NEGATION ARE THAT WAY AMBIGUOUS. This assumption, let us call it the ACROSS-THEBOARD ASSUMPTION of natural language negation, is a necessary requirement for his conclusion. Yet there is nothing in the available data that suggests that this assumption is correct. It is in fact, as I shall argue below, incorrect: there are pairs of positive and negative sentences where the negation necessarily preserves the presuppositions, and there are pairs of such sentences where the negation pointedly fails to do so. The difference depends on grammatical, lexical and idiomatic features of the sentence. My conclusion is, therefore, quite the opposite of Burton-Roberts: the ambiguity of not as intended here is not only falsifiably ascertainable, it is also really there.

It is generally not very clear what operational criteria will help us to 
distinguish, in any systematic way, vagueness from ambiguity. The literature contains some suggestions that do not work too badly to distinguish ordinary cases of lexical or syntactic ambiguity from vagueness. One generally accepted criterion for ambiguity is provided by Quine's famous passage (1960: 129):

Ambiguity differs from vagueness. Vague terms are only dubiously applicable to marginal objects, but an ambiguous term such as 'light' may be at once clearly true of various objects (such as dark feathers) and clearly false of them.

Another test to distinguish ambiguity from vagueness, much in use among linguists, was provided by Lakoff (1970). It is based on so do-pronominalisation of a preceding sentence $\mathrm{A}$. If $\mathrm{A}$ is ambiguous the so dopronominalisation continues the reading selected for $A$. In cases of vagueness there is no such continuation. For example, if the first conjunct in $(7 \mathrm{a})$, which is clearly ambiguous, is taken in one reading, then the second conjunct carries on on that same reading. But the first conjunct in $(7 \mathrm{~b})$ is vague, not ambiguous, as between for example whether the left or the right foot was used. Now, because this is vagueness and not ambiguity, the second conjunct is not restricted to the leg that may have been in the speaker's mind in the first conjunct:

(7) (a) Selma likes visiting relatives and so does Sam.

(b) Harry kicked Sam and so did Dave.

Other criteria for the distinction between ambiguity and vagueness are not too hard to find. For example, if a sentence A entails B in one context but fails to entail $B$ in a different context, without the context containing material necessitating $B$, then $A$ is ambiguous and not just vague. This follows from the fact that a difference in entailments implies a difference in truthconditions and hence a difference in meaning. Let us call this the ENTAILMENT CRITERION. We shall use it in a moment.

In any case, under these criteria Burton-Roberts' claim that it is impossible to demonstrate two readings if one entails the other is too strong. This appears, for example, with sentences containing the conjunction operator and, as has been observed by Horn (1985: 127). Such sentences are often ambiguous between a cumulative and a reciprocal reading, as is shown by:

(8) Sue and Dave are married.

Although the reciprocal reading entails the cumulative one, the two readings are clearly distinct and can be seen to be so under Quine's and Lakoff's criteria. Under Quine's criterion the ambiguity appears, for example, if (8) is 
placed in a context where it is false on the reciprocal but true on the cumulative reading, as in:

(9) A: Why are Sue and Dave so often together? Are they married?

B: No, Sue and Dave are not married. They are both deceiving their spouses.

If there were not some ambiguity in B's first sentence, which is the negation of (8), B's reply would be incoherent, since his second sentence implies that they are married, Lakoff's test yields the same result:

(I0) Sue and Dave are married, and so are Harry and Jim.

On the reciprocal reading of the first conjunct this sentence will cause some puzzlement precisely because the second conjunct continues this reading. But on the cumulative reading everything is as it should be. So there can be little doubt that, under these two criteria, (8) is ambiguous, and not vague, even though the one reading entails the other. ${ }^{8}$ Another, ad hoc, indication of ambiguity here is the fact that:

(I I) Both Sue and Dave are married.

only has the cumulative meaning. Clearly, the cumulative sense allows for the addition of both, but the reciprocal sense does not. It will be clear, anyway, that a claim of ambiguity does not imply a claim that the two postulated readings or senses are logically or semantically unrelated to each other.

However, as regards the possible ambiguity of not, the question of whether one reading entails the other need not even be relevant, since, as was pointed out earlier, it is not clear that minimally negated sentences entail their counterparts under the negation that cancels presuppositions. BurtonRoberts proceeds on the assumption that the ('external') negation operator that he presents as the presupposition-cancelling one in a trivalent logic is the classical negation $(\neg)$, not the radical negation. On p. 99 he gives the table for this alleged presupposition-denying negation, and this table is identical to that of $N_{3}$ in (6) above, in other words, classical negation. But we have seen that the two specific negations of a trivalent presuppositional calculus are the minimal negation $\left(=\mathrm{N}_{4}\right.$ of $(6)$ above) and the radical negation $\left(=\mathrm{N}_{2}\right.$ in (6)). Now, minimally negated sentences do Nor entail radically negated sentences. They entail classically negated sentences because, as we have seen, $\sim \mathrm{A} \vee \simeq \mathrm{A} \equiv \neg \mathrm{A}$. But Burton-Roberts fails to mention even the possibility of the radical negation operator, though, having consulted Seuren (I984) and (1985), he must have been aware of it.

[8] Zwicky and Sadock (1975), while allowing for possible ambiguity between two readings one of which entails the other ('privative opposites'), observe that such ambiguities will sometimes be hard to establish under the standard tests. This does not seem to apply to the ambiguity of (8). 
The question is again, therefore, a purely empirical one. And if not turns out to be best described as being ambiguous between a minimal and a radical (or at any rate presupposition-cancelling) reading, the logical space required for such an ambiguity is available. Unfortunately, however, Quine's and Lakoff's criteria are not easy to apply (cf. note 8). It is difficult to conjure up a situation where a sentence Not-A is 'at once clearly true' on one reading and 'clearly false' on the other. In the eyes of most researchers, this test is indecisive, which does not mean, of course, that there is no ambiguity, only that this test does not show it up if it is there. Lakoff's test fares a little better (at least in my view, not in the view of Kempson (1975: 100), whose examples, however, are too longwinded and involved to carry weight as evidence for speakers' intuitions). Consider the following sentence:

(I2) Jack has not come back and neither has Wilma.

The predicate come back induces the presupposition that the subject has been or is away. It would seem that (I2) can be followed coherently by either: They are both still away (in which case both conjuncts preserve the presupposition) or by: Because neither of them ever left. But a continuation like: Jack is still away and/but Wilma never left, which requires an interpretation where the first conjunct preserves the presupposition but the second does not, seems odd. Yet it is clear that this is not the kind of hard empirical evidence required for a serious claim that natural language not is ambiguous. The evidence for that claim comes from other sources.

Burton-Roberts refers to some of the relevant literature on the subject of the ambiguity of negation. Other publications can be mentioned as well. The overall impression one gets is clearly that the ambiguity tests currently in use fail to deliver an unambiguous result. Martin (1982), for example, argues extensively that the available tests, when applied to the available material, are indecisive for not (see also Seuren, 1985: 260-266). Gazdar's argument from translation (1979: 65) (if not were ambiguous why is it that no language seems to disambiguate between the two readings?) is widely considered to be a tough one for proponents of SAN. Yet it is not decisive. First, if not is indeed ambiguous between the readings that are at issue here, this is not an ordinary common or garden ambiguity, and we have no theory yet of such special cases of ambiguity. Then, we have just established the ambiguity of sentences like (8) above, and here, too, languages tend not to disambiguate. Moreover, even lexical ambiguities can be systematic and productive, and not language-particular. The verb work, for example, can mean 'be at one's paid job' or simply 'exert oneself in a constructive way', as in Rommetveit's (1983) example John is working, which is true on one reading but false on the other when John is busy in his garden on Saturday morning. Or take my answer No when I'm taking a snack in a roadside restaurant and have just been asked Are you a driver? I am, of course, a driver in one sense since my car is parked outside, but I am not a driver in the special sense intended, 
namely a professional lorry or bus driver. Such cases satisfy the standard ambiguity tests. There is really no known good reason to suppose that not should be somehow excluded from such semantic processes. Therefore, the 'argument from translation' is more rhetorical than logical. In other words, in the light of the evidence considered by Burton-Roberts one must conclude that the issue of SAN is wide open, and his unsuccessful attempt at preempting the issue on a priori grounds does not seem to add much to the debate.

Burton-Roberts has so far failed to establish anything that was not already generally known. But he defends (or adopts, for the sake of his argument see note I above) a view which is now considered to have been refuted. In particular, he adopts the Strawsonian view of presupposition, expressed in definition (1) and embedded in a two-valued logic with gaps. Consequently, his negation is as in (5), and thus presupposition-preserving. He has tried, without success, to impose this (aspect of his) view as somehow required by inherent properties of logico-semantic systems, in the face of available evidence. There is clear evidence, which has been accepted by the relevant scientific community for the past fifteen years, showing that in many cases natural language not does not preserve presuppositions as entailments (the cases where it does (see below) had not been observed and were thus unknown). Examples abound, for instance, in Wilson (1975), and they are all of the type:

(I3) (a) The king of France is NOT bald. There is no king of France.

(b) Donald has Not forgotten that we have a meeting. We don't have a meeting.

(c) Kate has NoT stopped smoking. She has never smoked in her life.

It was then assumed that this presupposition-cancelling ability of not, though only in contextually and intonationally heavily marked uses, was a general property of all uses of not, in other words the Across-the-Board Assumption mentioned above. Given this assumption, observations like those in (13) were taken by the majority of researchers as evidence of the untenability of the Strawsonian, and Burton-Roberts', position on presupposition, and with good reason. For if Not-A never by itself ENTAILS the presuppositions of A, then what are called presuppositions are, logically speaking, simply entailments, and there is thus no reason for tinkering with standard strictly bivalent logic, with just two truth-values and no gaps. We remember that the reason for introducing gaps was precisely the claim that both $\mathrm{A}$ and Not-A entail B if A presupposes B, while B is not a logically necessary truth.

If now Not-A is seen NoT to entail B in the cases of alleged presupposition, the bottom falls out of the whole notion of presupposition as a logicosemantic relation. Hence the title of Boër \& Lycan's well-known (1976) paper: 'The myth of semantic presupposition'. If presupposition is anything 
at all, it is not logico-semantic, was the general conclusion. The feeling was that it would be something pragmatic. This analysis is often called the ENTAILMENT ANALYSIS of presupposition, since it treats presuppositions, from a logico-semantic point of view, as just entailments. The Strawsonian position is thus seen to be untenable, since the only possible negation there preserves the presuppositions of the argument clauses. If one insists that presuppositions should be regarded as a logico-semantic relation, then what is needed is a truly trivalent logic with two distinct negations, namely with SAN. But this, it was said, is logically unnecessary, since classical logic will do the job. If one is unconvinced by possible contrary evidence based on ambiguity tests of the kind discussed above, and if one, moreover, accepts the Across-the-Board Assumption of natural language negation, there seems to be no fault with this reasoning.

But Burton-Roberts does find fault with it, though he is unconvinced by possible contrary evidence and accepts the Across-the-Board Assumption. He rightly treats cases like ( $13 \mathrm{a}-\mathrm{c})$ as 'special' or 'marked' (he is even ( 98 , Ioo) prepared to call them unnatural), yet he accepts them as possible. However, they 'are to be treated non-semantically, as instances of a pragmatic phenomenon' (95). This view is not new. It has been defended by a variety of authors, such as, for example, Atlas (1979) or Horn (1985). But none of these proposes that the logico-semantic negation should be the Strawsonian one, namely (5). If a commitment is made (Atlas (I979), for example, refrains from making one), it is to the classical negation in a bivalent logic without gaps, that is to a cancelling negation, and not to a presupposition-preserving negation. The general view (based on the Acrossthe-Board Assumption) is that presuppositions are sUGGesTED, but not ENTAILED, in negative sentences. And since logic is nothing to do with suggestions, this property must be kept out of the logic. Pragmatics seems an obvious haven. And the logic can stay the way it has always been: classical.

Burton-Roberts agrees with this, except on the point of the logic staying classical. He proposes that Not-A always entails the presuppositions of A, except in pragmatically strongly marked cases like those of (13) above, thereby placing a heavy burden on pragmatics. For while it is common, when appeals are made to pragmatics, to expect pragmatic theory to account for all kinds of suggestions (implicatures), ADDITIONAL to the hard logicosemantic entailments of sentence types, one rarely sees that pragmatic theory is expected to CANCEL hard entailments at type level. ${ }^{9}$

Burton-Roberts proceeds in the following way. He begins by proposing

[9] Note that we are dealing here with TYPES, that is with sentences as linguistic objects regardless of context, not TOKENS, or sentences uttered in specific contexts, even though the type level properties at issue may concern conditions for felicitous use in any context given. I do not contest, of course, that in certain contexts, e.g. when a sentence is uttered non-literally (in particular metaphorically), ironically, in quotation or other similar uses, the entailments carried by the sentence may become inoperative. 
that the marked character of presupposition-cancelling cases like those in (13), cases, that is, with a so-called 'echo', is in itself an argument for keeping them out of the logico-semantic system. This argument is found on p. 100:

It seems too descriptively implausible to suggest that an operation for which specific provision is made within the semantics should result in any feeling of specialness, markedness or unnaturalness when actually applied. On the contrary, the effect of incorporating such an operator within the semantics would be precisely to normalize that sense of negation. But this contradicts much of what a semantics of presupposition is supposed to account for.

I find this argument hard to follow. It takes for granted that 'marked' phenomena (in some reasonable notion of markedness, - and I will not deny that presupposition-cancelling negation comes into this category) per se fall outside the domain of a logico-semantic analysis of natural language sentences. The wider context of this passage makes it clear that BurtonRoberts follows common practice in more or less equating semantics with logic, opposing both to pragmatics. Logico-semantic analysis is thus supposed to 'normalize' the objects analysed, excluding marked cases. Clearly, the notion of markedness employed here is not any of the notions current in phonology or other areas of linguistics, where 'marked' cases are not considered in any way 'abnormal', and hence not falling under the terms of the analysis.

It is true that logic is standardly regarded as being about entailment and proof, so that it has no business with markedness phenomena. But there are also, nowadays, varieties of DEFAULT LOGIC, where a sentence $A$ is said to imply a sentence B by default, that is, normally, on the assumption that $A$ is conjoined with a set $G$ of general statements that are normally considered to hold. In such systems, G can be overruled, but only under special conditions, and by means of special operations. When that happens, the default inference is cancelled. If Burton-Roberts' argument were valid, this would mean that the concept of a default logic was incoherent or incongruous or whatever, because 'the effect of incorporating [a default-cancelling operation] would be precisely to normalize [it]', and this would 'contradict much of what [the notion of default] is supposed to account for'. In fact, however, there are sound and fully coherent default logics, with overrule conditions and all. Analogously, there is nothing incongruous or implausible in natural language having an operator available for use in marked cases.

The position commonly held by those who take presupposition-cancelling ('echo') negation to be a pragmatic and not a logico-semantic phenomenon is that the LOGICAL and/or SEMANTIC description of negation is simply the one provided by classical logic, whereas the overlay of echo and markedness is to be accounted for by some pragmatic theory. Such a position (though I believe it to be mistaken) makes much better sense than what is proposed by 
Burton-Roberts, mainly because it does not have to exclude from logic or semantics facts that are their very bread and butter, such as entailments. In short, Burton-Roberts attributes to logic and/or to semantics powers of 'normalization' which they do not possess, while at the same time keeping these disciplines out of their own legitimate territory. The 'normalization' argument is nothing but not too good rhetoric.

The next, equally rhetorical, step taken by Burton-Roberts is to cast doubt on the reliability of observations like those given in ( 13 ) above. On p. 104 we read:

At this point it might be asked: should we not be paying attention to the empirical (intuitive/pre-theoretical) facts of the matter by asking whether, as a matter of brute fact, (8)-(10) [that is, cases like ( 13 a-c) above - PAMS] are or are not semantically contradictory? My answer to this is that, as native speakers, we are not very good at making such judgments directly. Logical systems are supposed to help us in this. But in this case there are two types of logic available... In the absence of some quite compelling indirect evidence one way or the other, the decision is a theoretical one... In fact, however, there is compelling indirect evidence that they are indeed contradictory, as we shall see in the final section.

Burton-Roberts' lack of confidence here in his own powers of semantic observation should not be taken too seriously. A little later, while in the midst of his critique of Horn (1985), he assures his readers, with no lack of confidence (I I 4 ):

Negation is unequivocally understood as 'presupposition-preserving' in every case except those in which that understanding is starkly impossible - as in (8)-(10) above-in which cases it is, again unequivocally, understood as 'presupposition-cancelling'.

Moreover, while, as we have seen, on p. I05 trivalent systems are denied the function of reconstructing the intuitive notion of radically false statements, being 'purely formal systems', this function is granted them here, on p. 104. Then, as regards the 'compelling indirect evidence' promised for the final section, that sentence pairs like $(\mathrm{I} 3 \mathrm{a}-\mathrm{c}$ ) are literally contradictory (or, more precisely: contrary), I have done my best to detect that evidence, but to no avail. I think, in fact, that no such evidence is provided at all. All we find is the author's WISH that things should be that way (see (14e) below). And what's more, I think that such sentence pairs are perfectly consistent. Or else we should accuse Shakespeare of logical inconsistency when he treats us to the following little dialogue in The Taming of the Shrew (v.i.49), where Biondello lets his pitiless logic loose on poor Vincentio, who exclaims: 'Come hither, you rogue. What, have you forgot me?', whereupon Biondello replies: 'Forgot you! No, Sir: I could not forget you, for I never saw you before in all my life'. 
There is a further point, which makes it difficult for me to understand what Burton-Roberts' actual views are. As we have seen (see note 2 above), he only presents the 'standard' view of presupposition for the sake of his argument, explaining elsewhere (in particular in Burton-Roberts $1989 \mathrm{~b}$ ) what his real position is. In (1989b) he proposes that natural language not is NOT presupposition-preserving. His logic there is different in that negation cancels all contingent entailments of its argument clause. The result is that in (1989 b) pragmatics is called upon to explain why under negation presuppositions tend to be maintained as default assumptions (I989b: I48-I50). Quite unnecessarily, pragmatics is called on, in ( $1989 \mathrm{~b}$ ), also to explain the marked, metalinguistic character of negative sentences with presupposition cancellation. This would seem superfluous if the pragmatic account of default presupposition maintenance under negation is successful. Here, however, pragmatics is only assigned the task of explaining why and how under negation presuppositions are sometimes cancelled. The question is: what does Burton-Roberts actually hold? His pragmatic re-analysis of negation (discussed in the following section) suggests a fundamental shift from what he calls the 'revised theory of presupposition' in (1989b) back to the 'standard' notion which he rejected in (1989b). The fact that he now couples his pragmatic re-analysis of negation to the 'higher generalization' of (14d) below, would seem to show that the 'standard' notion presented at the outset was not just given 'for the purpose of the argument', but meant seriously. If so, one would expect an explicit statement to this effect. Yet, BurtonRoberts' writings are so baroque and verbose that it is, most of the time, difficult, and at any rate very time-consuming, to determine what he actually asserts. Anyway, if he has indeed reverted to the 'standard' notion of presupposition he has saved himself at least from logical disaster, since his ( 1989 b) notion is logically untenable (Seuren (to appear b)).

What is directly relevant here is Burton-Roberts' claim that logical inconsistency does not by itself make a sentence, or a set of sentences, unfit for actual use. The hearer will then, somehow, ignore the inconsistency and seek a 'pragmatic', non-truth-conditional interpretation of that text. Let us take a closer look at his pragmatic arguments as they are presented in his Sections 3-5. First, however, we must point to the fact that, so far, he has established nothing at all. He has failed to establish that a presuppositional semantics is incompatible with SAN, that is with a truly trivalent logic: that conclusion is seen to be based on a number of untenable implicit assumptions. Nor has he established that a bivalent logic with gaps, and thus with one unambiguous presupposition-preserving negation, is the only viable set-up for a logico-semantic analysis of language. We are left with the fact that this is simply how he wishes things to be. All right, provided no monopoly is claimed; let us see what Burton-Roberts' pragmatic re-analysis amounts to. 
3. BURTON-ROBERTS' PRAGMATIC RE-ANALYSIS OF NEGATION

The gist of the proposed pragmatic re-analysis of negation is as follows.

(14) (a) Whenever a given uttered negative sentence is somehow incongruous, for logical or other reasons, in its literal meaning in its context, it is re-interpreted non-literally so as to make sense in that context.

(b) Horn's (1985) cases of metalinguistic negation (MN) all have in common that the sentences in question are somehow contextually incongruous in their literal meanings.

(c) Those cases presented by Horn where the negation denies a (scalar) implicature or the appropriateness of a style or register selection are interpreted as being LOGICALLY inconsistent in their literal meanings.

(d) This, together with the thesis that not is unambiguous and minimal (in a bivalent logic with gaps), permits the formulation of a 'higher' (123) generalization to the effect that ALL of Horn's cases of MN can now be seen to be not only cases of 'quote' negation, that is $\mathrm{MN}$, but also of logical inconsistency. In Horn's own analysis (with classical negation in classical logic, in other words the entailment analysis), cases like ( $\mathrm{I} 3 \mathrm{a}-\mathrm{c}$ ) are not logically inconsistent.

(e) Hence it is preferable to take natural language not as being MINIMAL in a bivalent logic with gaps: that makes cases of presupposition denial, such as ( $13 a-c)$, logically inconsistent.

Let us consider these successive steps in more detail.

Step ( $14 \mathrm{a}$ ) in this argument is hard to assess. It is clearly true that logical inconsistency of a literal meaning is sometimes overlooked or ignored in verbal communication, to be replaced by a non-literal interpretation (see also note 8 above). But this cannot be a reason for dispensing with logic. Indeed, just the opposite is the case because (i) there is no reason to assume that 'nonliteral' interpretations are not subjected to the same rules of the same logic that reigns in other forms of verbal communication, and (ii) little or nothing is known about the CONDITIONS or the MODALITIES of non-literal interpretation. As presented by Burton-Roberts, ( $14 \mathrm{a}$ ) is perilously wide, and perilously ad hoc, the latter because no reason is given for the restriction to negative sentences when it comes to letting go of logic. One wonders, for example, why the entailment from 'being murdered' to 'being dead' is not cancellable on 'pragmatic' grounds in cases like (I5), which remain anomalous in any thinkable context where both sentences are asserted successively by the same speaker:

(I5) !Jonathan has been murdered. He isn't dead. 


\section{BURTON-ROBERTS' CONTENTIONS}

Admittedly, (I5) is a lot better, and even perhaps acceptable, if but is inserted at the beginning of the second sentence, though some further explanation of this glaring inconsistency is then required by any serious listener. But then the question arises why such insertion of but is grossly inappropriate in an example such as, (I $3 \mathrm{a})$, which, with but, is totally unacceptable:

(I6) ! The king of France is NOT bald. But there is no king of France.

Causal for, or since, is much better in (I6), as was demonstrated above by Shakespeare's Biondello, but insertion of for or since in (15) leads again to uninterpretability. It will be clear that, while possible insertion of but may be taken as a sign that an apparent lack of consistency is being compensated for, possible insertion of for or since points on the contrary to consistency, whether logical or inductive or other.

Even if restricted to negative sentences, however, (I4a) remains perilously wide, at least in terms of Burton-Roberts' analysis. For why should pragmatic compensation in his sense be excluded in a case of sentence negation like ( $17 \mathrm{a})$ but allowed in a case like $(17 \mathrm{~b})$ :

(17) (a) ! John did not stay till the end. (For/But) he sat it all out.

(b) $\sqrt{ }$ John did not stay till the end. (For) he was never there.

The sentence John did not stay till the end entails that he did not sit it all out (because that he sat it out entails that he stayed till the end), and, according to Burton-Roberts, also that he was there. Yet in $(17 \mathrm{~b})$ the denial of the entailment can be repaired (though by for and not by but), whereas in (17a) it cannot. The difference is that the offending entailment in (17a) is not presuppositional, whereas in ( 17 b) it is. So, if Burton-Robert's analysis is correct, it is just presuppositional entailments of negative sentences that allow for entailment cancellation. It would seem, at this point, that the question of what precisely singles out presuppositional entailments for cancellation under pragmatic protection is entirely legitimate. This question is not answered by Burton-Roberts.

In short, while it is true that non-literal interpretation is sometimes called for in the analysis of verbal communication, any such appeal should be supported by at least some specification of the conditions under which this is possible. Conversational settings require that the hearer will fall back on any rule in the book in order to make sense of utterances he hears. But there still is a book, with rules. And there is nothing to suggest that logic is not part of that book, or that secondary or non-literal interpretations are not subject to the same principles of grammatical and semantic analysis that are found valid for literally interpreted sentences. Without any indication as to what the boundaries are for non-literal interpretations, a claim like that made in (14a) is relatively empty. 
Now to (I 4 b) and (I4c). The validity of these points depends on what one takes to be the 'literal meaning' of a sentence. Take Burton-Roberts' (I8):

(I 8) I didn't trap two mongeese. I trapped two mongooses!

It is a simple fact of linguistic observation that in its most literal interpretation (I8) expresses a double assertion about the inappropriateness of the word mongeese as against the propriety of mongooses. I can see neither a contextual incongruity nor a logical inconsistency here, and hence no necessity for any kind, pragmatic or other, of re-analysis of the negation in the first sentence.

This being so, an adequate grammar of English must contain a rule mechanism to relate the surface form of (18) with a semantic analysis approximately like:

(19) Not [the $\mathrm{x}$ [such that ' $I$ trapped two $x$ ' is properly said] is 'mongeese']; the $\mathrm{x}$ [such that ' $I$ trapped two $x$ ' is properly said] is 'mongooses'

Prima facie such a rule mechanism is not implausible, given the accentual pattern that is required for (18), with contrastive accent on mongeese and mongooses, respectively. Contrastive accent is a sure sign of a semantically underlying cleft form of the general structure 'the $x[$ such that ...x...] be NP. A rule (which I have called Predicate Lowering; Seuren, 1985: 302) lowers the NP into the relative clause on to the position of $x$, deleting all higher structure, but placing contrastive accent on the NP. Application of this rule to (19) gives 'I trapped two mongeese' is not properly said; 'I trapped two mongooses' is properly said. What is needed now is a rule that (optionally) deletes 'be properly said'. But that rule is patently at work in language, not only for what is said but, more generally, for anything done or performed. ${ }^{10}$ What else could be the analysis and the function of one's corrective utterance: ELDERLY women you mean, after someone has just been speaking of old women? Under such an analysis, which corresponds directly to the way (I8) is understood, there is nothing non-literal or non-truth-conditional about (18). ${ }^{11}$ Yet the grammar is not at issue here. What is at issue is merely the observational fact that (18) means what it means, which is expressed in (19).

As regards ( $14 \mathrm{~d}$ ) and (14e), we have already seen that both our intuitive judgment and other indications, such as the insertability of for or since to give the REASON for the presupposition denial, strongly support the view that presupposition denials such as ( $13 \mathrm{a}-\mathrm{c}$ ) are perfectly consistent. The 'higher' generalization wanted by Burton-Roberts is thus entirely of his own making and lacks factual support.

[10] Cf. Horn's amusing example of the piano teacher correcting a pupil's playing (Horn, 1985: 136), where the deletion affects 'be properly played'.

[II] Note that the analysis as given in (19) does not, as one reviewer feared it might do, obliterate the distinction between mention and use. This is clear from the fact that in (19) quoted elements occur as part of the analysis. What happens is that the GRAMMAR obliterates the distinction, as it does with so many other semantic distinctions. 


\section{BURTON-ROBERTS' CONTENTIONS}

This is really all that is offered by Burton-Roberts in the way of pragmatic argumentation. He does not explain why and how not can assume precisely the pragmatic function attributed to it: the derivation of the pragmatic from the semantic sense remains almost totally obscure. He joins other authors, notably Horn (1985), in saying that not, in its pragmatic sense, signals the 'rejection' of a previously uttered sentence, which is then 'sealed off' by quotation marks and catapulted into the limbo of contextually unacceptable sentences. I believe that this is in principle correct, at least for cases of presupposition denial, but it does not say much as long as not even a sketch is given of the mechanisms underlying processes of this nature. ${ }^{12}$ Moreover, in its vagueness this intuitive analysis is also too wide, since it is clearly not so that just any kind of utterance can be 'rejected' by the use of not. Suppose, for example, that you and I are discussing a certain politician, whom I think is a crook and a hypocrite, but who in your eyes is an honest and competent man. I say, quoting Anthony's famous words in Shakespeare's Julius Caesar: 'And Brutus is an honourable man'. You become angry with me, and want to reject my utterance in the strongest possible way. It will be clear that you cannot now say: 'And Brutus is NOT an honourable man!'. You might exclaim: 'To hell with your Brutus', or something similar. But the negation word not is unsuitable for this case. The question is: why is it unsuitable here? Neither Burton-Roberts nor the other pragmatically inclined authors answer questions of this kind.

It should be mentioned that Burton-Roberts presents a rather odd argument to the effect that on the entailment analysis of presuppositions there can be no reason why a pragmatic re-analysis of negation would be called for anyway. We read (120):

What, on a non-presuppositional semantics, would trigger, and provide the rationale for, a pragmatic re-analysis of the negation as metalinguistic?

The answer is: nothing whatsoever. The pragmatic re-analysis arises from the need to solve a problem. On a non-presuppositional analysis there is no problem...; the negation is semantically analysed as an ordinary, straightforward, truth-functional denial.

Without wishing to defend the entailment analysis, which I think is false, I feel that this critique is entirely without foundation. In the entailment analysis, presuppositions are interpreted as entailments from a STRICTLY LOGICAL point of view. But this does not mean that logic is thought to tell the whole story. On the contrary, it is very clear from the literature (cf. Wilson, I975, which I, oddly, seem to be defending here) that from a PRAGMATIC point of view a presupposition is considered to have the special property of contributing to the contextual or conversational acceptability of its carrier sentence. This is then taken to account for the fact that the carrier sentence,

[12] For a detailed attempt at a formal and technical analysis of this notion, see Seuren (1988). 
if negated, still carries the suggestion, though not the entailment, that its presuppositions are fulfilled, since a negative sentence should, on the whole, be equally acceptable, in a given context or conversational setting, as its positive counterpart. The pragmatic re-analysis of not as a metalinguistic negation in a presupposition-denying negative sentence is thus 'triggered' by the fact that this use of the negation stamps the whole carrier sentence as being contextually or conversationally inappropriate. In putting the case as he does, Burton-Roberts seriously misrepresents the position of those he criticises.

It will be clear that his third contention, namely that his proposed pragmatic re-analysis of not as metalinguistic negation 'itself implies a presuppositional semantics' consisting of 'a presuppositional theory of truthvalue gaps', is not supported by any kind of serious argument. There is a certain amount of suggestive prose, or rhetoric, if you like, but no cogency.

\section{THE EMPIRICAL UNTENABILITY OF BuRton-ROBERTS'POSITION}

The situation is actually worse. Burton-Roberts' position not only lacks sufficient logical, theoretical and empirical backing, as has been argued. It is also in positive conflict with available evidence. This evidence shows that his position, and in general the notion of a pragmatic re-analysis of negation, is not tenable. What is required is a strictly semantic analysis of presuppositional phenomena, to be flanked by a corresponding lexical and grammatical analysis on the one hand, and a corresponding logic on the other. Most of this evidence has been presented in Seuren (1984) and (1985); it is presented again, and expanded, in Seuren (I988).

The gist of the evidence is a denial of the Across-the-Board Assumption for natural language negation, which, as we have seen, is essential to both the entailment analysis and Burton-Roberts' neo-Strawsonian position. If all uses of not, or the corresponding negation word in other languages, were similar in that they SUGGEST the presuppositions of the non-negative carrier sentence while at the same time ALLOWING FOR the cancellation of this suggestion under certain pragmatically defined conditions, it would be, I think, very hard to argue against the entailment analysis. The crucial point now is that this condition is not fulfilled. For many, perhaps most, uses of negation there is indeed the suggestion that the presuppositions of the carrier sentence hold, together with the contextually conditioned possibility of cancellation, as was observed by the entailment analysts. But there are also cases where, under negation, some or all of the presuppositions of a sentence are fully preserved as entailments, without any possibility of cancellation, and at the other end there are cases where not even the suggestion of some or all of the original presuppositions is maintained. The cases of necessary presupposition preservation are primary evidence against the entailment analysis. The cases of necessary presupposition cancellation weaken the 
entailment analysis to the extent that they make it harder for a pragmatic theory to account for the difference with the other class of presuppositioncancelling negative sentences where the original presupposition remains in a weakened form as a suggestion or, as I have called them elsewhere (Seuren, to appear a), as a 'default assumption'. In so far as this evidence undermines the entailment analysis it is new. The cases of presupposition cancellation, with or without a remaining presuppositional suggestion, tell squarely against Burton-Roberts' position.

Whether a negated sentence falls into the class of full logically valid presupposition maintenance or of total cancellation, or, for that matter, of a combination of the two (which then necessarily amounts to an ambiguity, though with a, probably pragmatically based, preference for presupposition maintenance), depends on the SYSTEM Or TYPE PROPERTIES of that sentence, and not on CONTINGENT CIRCUMSTANCES OF USE in specific contexts (even though the type properties in question may consist of systematic conditions on the sort of context in which the sentence in question can be used intelligibly). If we accept that semantics, logic and grammar provide descriptions and analyses on a type level, whereas pragmatic looks at the interaction of type-level structures and token-level actual speech situations, it follows that the distinctions in possible negation use at issue here are a matter for semantics (with grammar and logic as indispensable companions), and clearly not for pragmatics.

Since Burton-Roberts ( $12 \mathrm{I}-122)$ badly misrepresents the evidence at issue, making it look as though only cases with Negative Polarity Items are brought to bear in Seuren (1984; 1985), I shall, in succinct form, present the gist of the evidence again here. It consists mainly of pairs of positive and negative sentences, where the negative sentence either preserves some or all of the presuppositions of the positive sentence as full entailments that cannot be cancelled, or cancels all these presuppositions, not even leaving the trace of a default assumption, suggestion or implicature. Consider, for example, the following pairs, where the negative member seems to keep the presuppositions of the positive member as full, uncancellable entailments:

(20) (a) That the burglar was holding a knife frightened the cook.

(b) That the burglar was holding a knife did not frighten the cook.

(Both entail: the burglar was holding a knife.)

(21) (a) What she did was cry for help.

(b) What she did was not cry for help.

(Both entail: she did something.)

(22) (a) It was the roof that caught fire first.

(b) It wasn't the roof that caught fire first.

(Both entail: something caught fire first.) 
(23) (a) The Roof caught fire first.

(b) The ROOF didn't catch fire first.

(Both entail: something caught fire first.)

(24) (a) Only Jack was convicted.

(b) Not only Jack was convicted.

(Both entail: Jack was convicted.) $)^{13}$

(25) (a) All the spark plugs have been renewed.

(b) Not all the spark plugs have been renewed.

(Both entail: there were spark plugs.)

(26) (a) That lack of courage kept him from telling the truth.

(b) That lack of courage did not keep him from telling the truth.

(Both entail: he had a lack of courage.)

(27) (a) It does matter that her experiment had clear results.

(b) It does not matter that her experiment had clear results.

(Both entail: her experiment had clear results.)

(28) (a) Repeating the experiment was easy.

(b) Repeating the experiment was not easy.

(Both entail: the experiment had been done before.) $)^{14}$

In all these cases a presupposition of the (a)-sentence is preserved under semantic sentence negation with no possibility of cancellation: all (b)sentences are clearly felt to be incompatible with the negation of the entailed presupposition.

By way of contrast there are other cases where the presupposition is completely neutralized. These are mostly cases where a Positive Polarity Item (italicised in the examples) comes to stand directly under not. Only (33) is a case where no Positive Polarity Items seems to play a role. All cases of presupposition cancellation, whether a Positive Polarity Item is at play, as in (29)-(32), or not, as in (33), carry a clear 'echo' effect (calling for a special intonation), which means that the non-negated sentence has been explicitly uttered or at least strongly suggested in preceding discourse, and that the negation denies its contextual appropriateness. The non-entailment sign in

[13] As has been pointed out by Horn (1969), if only is replaced with even we also get a sentence pair with a common entailment, namely that Jack was accused. But Not even Jack was convicted is not the semantic negation of Even Jack was convicted. The former can only be analysed as 'Even Jack was not convicted', and the semantic negation of the latter can only be expressed as something like It is not true that even Jack was convicted, due to even being a Positive Polarity Item (see below).

[14] As one reviewer rightly noted, scalar implicatures are easily cancelled:

(i) Not all the spark plugs have been renewed - and indeed, it may turn out that none of them have been.

(ii) Repeating the experiment was not easy - and in the end it turned out to be impossible. This illustrates quite clearly the difference between scalar implicatures and presuppositions. 


\section{BURTON-ROBERTS' CONTENTIONS}

the (b)-sentences is meant to imply, in addition, that even the suggestion of the non-entailed sentence (the presupposition) is weakened to the point of non-existence : $:^{15}$

(29) (a) They soon regretted their decision. $\vDash$ They made a decision.

(b) They did not soon regret their decision. $\not \neq$ They made a decision.

(30) (a) She staunchly supported her brother. $\vDash$ She had a brother.

(b) She did not staunchly support her brother. $\not \equiv$ She had a brother.

(3I) (a) He drank some of the wine. $\vDash$ There was wine.

(b) He did not drink some of the wine. $\not \neq$ There was wine.

(32) (a) They had plenty of time to repeat the experiment. $\vDash$ They did the experiment before.

(b) They did not have plenty of time to repeat the experiment. $\not \neq$ They did the experiment before.

Examples of this kind can be constructed at will: every language has a large number of Positive Polarity Items, whose typical property it is precisely to provoke an 'echo' when placed under negation, and then also to cancel all presuppositions. In (33), exceptionally, no Positive Polarity Item seems to occur The positive (33a) is intended in the reading where it is entailed that he did in fact not hurt her, not in the reading where she first turned the key and then got hurt. Note that ( $33 \mathrm{~b})$, though lacking a Positive Polarity Item, still has its echo:

(33) (a) She turned the key before he had a chance to hurt her. $\models$ There was a key.

(b) She did not turn the key before he had a chance to hurt her. $\not \neq$ There was a key.

No explanation is available as yet of why not behaves so differently in different constructions. All we can do at the moment is OBSERVE that it does. Given these observations, a pragmatic explanation seems excluded, if only because the way the negation behaves in all such cases does not depend on contingencies of context and/or situation but is observably there independently of any specific context. As in the case of (8) above (i.e. Sue and David are married), we are practically forced to admit that those cases where the negation is allowed to cancel presuppositions, as for example:

(34) The king of France is not bald.

[15] It must be noted that this does not apply to cases where the (b)-sentences are taken in the 'quote' reading, as when $(29 \mathrm{~b})$ is said because they did so immediately. The metalinguistic echo reading intended for the (b)-sentences is thus clearly different from their quote reading, which is one more argument for my thesis (Seuren, 1988) that Horn's MN covers a heterogeneous class of phenomena. 
are SEMANTICALLY and hence LOGICALly ambiguous. This does not imply that it is the negation word not itself that is ambiguous, though that is, of course, a favourite hypothesis. In the same way the ambiguity of (8) does not imply that it is the conjunction and which carries the ambiguity. (In fact, I believe that and is not ambiguous and that the ambiguity of (8) follows from the lexical properties of the verb marry and the fact that NP constituents are built up grammatically from propositional structures. But this point cannot be elaborated here.) It may be that the ambiguity of sentences like (34) springs from other elements in the sentence than the negation word, and if this ambiguity can be bought without the extra cost of an ambiguous negation or of other ambiguities to be introduced just for this purpose, then, clearly the idea of an ambiguous negation must be rejected. However, no such alternative analysis has so far been proposed with any degree of conviction. ${ }^{16}$

Moreover, as has been observed, for example in Seuren (1984) and (1985), one notices that the negation that fulfils the requirement of negativity posed by Negative Polarity Items in non-complex assertive main clauses can only be the minimal, presupposition-preserving negation. Clearly, in most of such cases there is no non-negative counterpart, though in some cases there is, as in $(27 \mathrm{a}, \mathrm{b})$, where the Negative Polarity Item matter (which is at the same time a factive verb) allows for an emphatic positive with do-support. Consider, for example, the following sentences, where the Negative Polarity Items are italicised:

(35) (a) She doesn't live in Paris any more. ( $\vDash$ she has lived in Paris before now)

(b) She wasn't all that cruel to her dog. ( $\vDash$ she had a dog)

(c) He didn't as much as touch the guy. ( $=$ there was a guy)

(d) He hasn't kicked his dog in weeks. ( $=$ he has a dog)

Although these sentences have no direct non-negative counterpart, they demonstrate again the exclusion of the presupposition-cancelling negation, and thus reinforce the position that not is indeed ambiguous, as both in (II) strengthens the view that (8) is ambiguous. Note that, in this analysis, Negative Polarity Items require the minimal negation and exclude the radical negation, whereas Positive Polarity Items allow for the radical negation but exclude the minimal one. Both classes of items are thus seen to behave more symmetrically in this than in the standard strictly bivalent analysis.

Burton-Roberts (122) presents my position as depending solely on the obligatory minimal character of not with Negative Polarity Items. It will be

[16] Van der Sandt's 'echo operator' analysis (Van der Sandt, to appear), discussed in Seuren (1988), is still in too weak a shape to be taken as a serious alternative. 
clear that this is, as I have said, a serious misrepresentation. He does not make things better by going on as follows (ib):

A further compelling argument against Seuren's position on this is the fact that negative polarity items fail to be triggered in ALL OTHER CASES of what I and Horn wish to regard as the same phenomenon of metalinguistic negation, including cases where what is being objected to is self-evidently independent of the semantics, e.g. where pronunciation, morphology, or style are being objected to. To maintain his position, Seuren must either claim that pronunciation, morphology and style do come within the scope of the relevant semantic operator or forego the obvious intuitive generalization that all these negations fall together as a single phenomenon.

I have elsewhere (Seuren, I988) commented amply on Horn's thesis that all cases of what he (rightly) calls 'metalinguistic negation' fall naturally into the same class. Horn, and Burton-Roberts (and a few others) are, in my view, mistaken on this. First, cases of utterance correction, such as (cf. BurtonRoberts 1989b: 15):

(36) (a) Granny isn't feeling lousy, Johnny, she's badly indisposed!

(b) I'm not happy, I'm ecstatic!

(c) That car isn't old, it's antique!

(d) I didn't eat the [ $\left.\mathrm{t}^{\mathrm{h}} \mathrm{a}^{\prime} \mathrm{meID} \mathrm{D}\right]$, I ate the [ $\left.\mathrm{t}^{\mathrm{h}} \mathrm{a}^{\prime} \mathrm{ma}: t a u z\right]$ !

(e) The President hasn't lied about the letter he wrote to the Ayatollah, he hasn't, perhaps, wished to divulge all relevant aspects of the matter.

are precisely that: they are assertions about proper pronunciation or adequate linguistic usage, and as such 'metalinguistic' from a logical point of view, but just sentences from a linguistic point of view (cf. the discussion on (18) and (19) above). And there is no reason to deny ordinary truthconditionality, or, for that matter, presuppositions, to such sentences. But the presuppositions are those that come with statements about linguistic objects, not, or not necessarily, those that come with the sentences themselves that are quoted. Then, the negation in such cases is minimal, not radical, as appears, for example, from the fact that $(36 \mathrm{e})$, though consisting of two negative conjuncts, still presupposes that the President sent a letter to the Ayatollah. This class of uses of metalinguistic negation is therefore distinct from the class of presupposition-cancelling negative sentences, such as those presented in (29)-(32), where the negation is radical.

Moreover, contrary to Burton-Roberts' rash statement, Negative Polarity Items do normally occur in, let us say, the Horn cases, as exemplified in 
$(36 a-e)$. Consider, for example (with the Negative Polarity Items again italicised):

(37) (a) We aren't eating [ $t^{\mathrm{h}} \partial^{\prime} \mathrm{ma}$ :təuz] anymore. From now on its [ $\mathrm{t}^{\mathrm{h}} \mathrm{\partial}^{\prime}$ merDoz] we eat.

(b) That car isn't old at all. It's antique.

This shows that Burton-Roberts' argument against Seuren's position' is not compelling at all. It is simply based on deficient observation.

\section{Conclusion}

In summary, it doesn't seem as though Burton-Roberts has much of a case in defending a neo-Strawsonian notion of presupposition (as, in fact, he didn't in defending his other notion of presupposition, the one presented in his $(1989 \mathrm{~b})$ ). His analysis of the logical situation is (again) seen to be defective, in particular as regards the distinction between what constitutes a truth-value gap and what a third truth-value. His arguments for and method of pragmatic re-analysis of negation are seen to lack substance (more so this time than in (1989 b)). And finally, his treatment of the available data (to say nothing of his opponents' views) lacks the care that is called for in such matters (and this was likewise a striking feature of his ( $1989 \mathrm{~b})$ ). The upshot is, unfortunately, that I for one, in spite of having devoted considerable time and attention to Burton-Roberts' writings on the subject, have not been able to see what positive contribution they have made so far to the current debate on presuppositions.

Author's address: Filosofisch Institut,

K.U. Nijmegen,

Aquinostraat 3,

Nijmegen,

The Netherlands.

\section{REFERENCES}

Atlas, J. (1979). How linguistics matters to philosophy: presupposition, truth, and meaning. In Oh, Ch.-K. \& Dinneen, D. A. (eds.), Presupposition ( = Syntax and Semantics II). New York, San Francisco, London: Academic Press. (p. ref. given by Burton-Roberts)

Boër, S. \& Lycan, W. (1976). The myth of semantic presupposition. Indiana University Linguistics Club.

Burton-Roberts, N. (1989a). On Horn's dilemma : presupposition and negation. JL 25. 95-I 25.

Burton-Roberts, N. (1989 b). The limits to debate. A revised theory of presupposition. Cambridge:

Cambridge University Press.

Dummett, M. (1973). Frege: philosophy of language. London: Duckworth.

Gazdar, G. (1979). Pragmatics, implicature, presupposition, and logical form. New York, San Francisco, London: Academic Press.

Horn, L. (1969). A presuppositional analysis of 'only' and 'even'. Chicago Linguistic Society 5. 98-107.

Horn, L. (1985). Metalinguistic negation and pragmatic ambiguity. $L g$ 6I. I2I-174.

Kempson, R. M. (1975). Presuppositions and the delimitation of semantics. Cambridge: Cambridge University Press. 


\section{BURTON-ROBERTS' CONTENTIONS}

Lakoff, G. (1970). A note on ambiguity and vagueness. LIn I. 357-359.

Martin, J. N. (1982). Negation, ambiguity, and the identity test. Journal of Semantics 1. 25 I-274. Quine, W. V. O. (1960). Word and object. Cambridge, MA.: MIT Press.

Rommetveit, R. (1983). In search of a truly interdisciplinary semantics. Journal of Semantics 2. I-28.

Seuren, P. A. M. (1984). Logic and truth-values in language. In Landman, F. \& Veltman, F. (eds.), Varieties of formal semantics. Dordrecht: Foris. 343-363.

Seuren, P. A. M. (1985). Discourse semantics. Oxford: Blackwell.

Seuren, P. A. M. (1988). Presupposition and negation. Journal of Semantics 6. 176-228.

Seuren, P. A. M. (to appear (a)). Presupposition. In von Stechow, A. \& Wunderlich, D. (eds.), Handbuch der Semantik. Berlin: De Gruyter.

Seuren, P. A. M. (to appear (b)). Review of Burton Roberts (1989 b). In Linguistics.

Van der Sandt, R. A. (to appear). Discourse systems and echo quotation.

Van Fraassen, B. (1971). Formal semantics and logic. New York \& London: Macmillan.

Weijters, A. (1985). Presuppositional propositional calculi. In Seuren (1985): Appendix. 483-525.

Wilson, D. (1975). Presuppositions and non-truth-conditional semantics. London, New York, San Francisco: Academic Press.

Zwicky, A. M. \& Sadock, J. M. (1975). Ambiguity tests and how to fail them. In Kimball, J. P. (ed.), Syntax and Semantics Vol. 4. New York, San Francisco, London: Academic Press. $\mathrm{I}-36$. 